\title{
No Evidence for an Association Between Variability in Sulcal Pattern and Academic Achievement
}

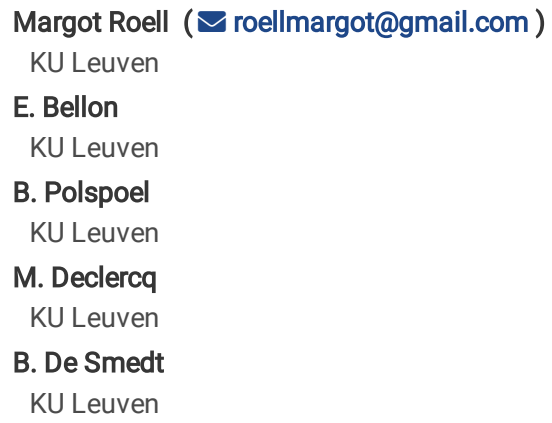

Research Article

Keywords: Sulcal morphology, Academic abilities, reading, mathematical abilities, intraparietal sulcus (IPS), occipitotemporal sulcus (OTS)

Posted Date: August 31st, 2021

DOI: https://doi.org/10.21203/rs.3.rs-332161/v2

License: @ (1) This work is licensed under a Creative Commons Attribution 4.0 International License. Read Full License 


\section{Abstract}

Investigating how the brain may constrain academic achievement is not only relevant to understanding brain structure but also to providing insight into the origins of individual differences in these academic abilities. In this pre-registered study, we investigated whether the variability of sulcal patterns, a qualitative feature of the brain determined in-utero and not affected by brain maturation and learning, accounted for individual differences in reading and mathematics. Participants were 97 typically developing 10-year-olds. We examined (a) the association between the sulcal pattern of the intraparietal sulcus (IPS) and mathematical ability; (b) the association between the sulcal pattern of the occipitotemporal sulcus (OTS) and reading ability; and (c) the overlap and specificity of sulcal morphology of IPS and OTS and their associations with mathematics and reading. Despite its large sample, the present study was unable to replicate a previously observed relationship between the IPS sulcal pattern and mathematical ability and a previously observed association between the Left posterior OTS sulcal pattern and reading. We found no evidence for a possible overlap or specificity in the effect of sulcal morphology on mathematics and reading. Possible explanations for this absence of an association between sulcal morphology and academic achievement and suggestions for future research are discussed.

\section{Introduction}

Understanding how academic abilities, such as reading and math, develop but also mapping the various constraints, including biological factors, that may influence its development is of great importance for both science and society. Especially since research suggests that these academic abilities are important factors in determining career success, income and even psychological well-being (e.g., Parsons \& Bynner, 2005). Yet, the 2018 Program for International Student Assessment (PISA) results show that more than one in five pupils in the EU has insufficient proficiency in these key academic skills (OECD, 2019). Investigating how the brain may constrain academic achievement is not only relevant to understanding brain structure but also to providing insight into the origins of individual differences in these academic abilities.

Research has extensively studied the function of key regions for processing mathematics and reading, namely bilateral intraparietal sulcus (IPS, see Menon, 2014; Peters \& De Smedt, 2018 for a review) and the Left occipito-temporal sulcus (OTS) host of the visual word form area (VWFA, Dehaene \& Cohen, 2011), respectively. Much less studies have examined how individual differences in the structure of these regions are related to differences in academic performance (e.g., Evans et al., 2015; Isaacs et al., 2001; Richlan et al., n.d.; Torre \& Eden, 2019). Even less studies have investigated the long-term effect of early brain development on later mathematical and reading abilities. Specifically, such study of early cerebral constraints on math and reading would allow us to further unravel the question of causes of individual differences in academic learning. Recent studies have found evidence of associations between a marker of early brain development, sulcal morphology, and academic achievement, i.e. reading (Borst et al., 2016; Cachia et al., 2017) and mathematics (Roell et al., in prep). The aim of this study was to replicate and extend these findings of an association between the sulcal morphology of the IPS and math abilities as well as the sulcal morphology of the OTS and reading.

Research has strived to delineate the brain regions functionally supporting mathematical ability. This body of literature converges to suggest that a frontoparietal network is engaged during arithmetic in both children and adults (Arsalidou \& Taylor, 2011; Peters \& De Smedt, 2018; Rivera et al., 2005). Consistent across these data is the activation of the bilateral IPS during arithmetic (e.g., Arsalidou \& Taylor, 2011; Peters \& De Smedt, 2018). Importantly, imaging studies in children have shown that activity in the arithmetic fronto-parietal network is modulated by individual differences. Specifically, children with low arithmetic fluency have been found to show a higher activity in, particularly the Right, IPS (De Smedt et al., 2011; Demir-Lira et al., 2016; Price et al., 2013). The activation of the IPS has also been consistently associated with basic number processing, such as symbolic number comparison (Fias et al., 2003; Holloway \& Ansari, 2010; Vogel et al., 2013). IPS activation for symbolic numbers has been found to be cross-culturally consistent, as the IPS number-related activity has been found to be similar in Eastern and Western populations (Eger et al., 2003; Kazui et al., 2000; Prado et al., 2011; Zhou et al., 2007). Importantly, studies have shown that over the course of development, symbolic number comparison abilities are associated with a progressive specialization of the IPS (Ansari, 2008; Holloway \& Ansari, 2010). Children with developmental dyscalculia, a deficit in arithmetic and number processing (American Psychiatric Association, 2013), have been found to have impairment in the IPS when processing number magnitudes and performing calculations. That is, the IPS is not modulated in response to numerical processing demands to the same degree as typically developing children (Mussolin et al., 2010; Price et al., 2007).

Studies have also investigated which brain structures are related to individual differences in mathematical ability, with the majority of studies focusing on the role of white and grey matter. Individual differences in math ability were found to be associated with higher fractional anisotropy, a parameter related to white matter microstructure, in white matter tracts connecting frontal lobes with basal ganglia and parietal regions (Matejko et al., 2013; Navas-Sánchez et al., 2014; van Eimeren et al., 2008). Additionally, grey matter volume of the Left IPS at the end of first grade has been found to be related to math competence a year later at the end of Grade 2 (Price et al., 2016). Similarly, Evans et al. (2015) reported that grey matter volume of posterior parietal areas, including the Left IPS, predicted the growth in arithmetic across primary school. However, in a recent study, Polspoel et al. (2020) examined grey matter volume using voxel-based morphometry, as did previous studies, but also cortical complexity. They did not find a significant association between children's arithmetic fluency and the grey matter volume or the complexity of parietal regions such as the IPS.

Reading, on the other hand, systematically activates the Left lateral Occipitotemporal sulcus (OTS) at a fixed location known as the Visual Word Form Area (VWFA, Cohen et al., 2002) relative to a reproducible mosaic of regions partially specialized for objects, faces, bodies and places (Downing et al., 2006). The specialization of the VWFA site appears progressively as children start to learn to read (Dehaene-Lambertz et al., 2018). Additionally, word-induced activation found at the site of the VWFA in good readers has been found to be cross-culturally consistent. Bolger et al.(2005) found that the peak activation of the VWFA in Japanese kana, Japanese logographic kanji, Chinese and roman alphabet readers was all within the millimeter of each other. Furthermore, children and adults with developmental dyslexia, a specific disorder of reading acquisition (American Psychiatric Association, 2013), show an under-activation (Cao et al., 2006; Shaywitz et al., 2003) and a dysfunction in the VWFA whilst processing visual words (van der Mark et al., 2011). 
Studies have also examined the brain's structure supporting reading, again focusing largely on white and grey matter data. In their study, Myers et al. (2014) found that increases in the volume of two left temporo-parietal white matter clusters are unique predictors of reading outcomes above and beyond family history, socioeconomic status and cognitive and preliteracy measure at baseline. Similarly, Niogi \& McCandliss (2006) found a strong correlation between fractional anisotropy values in a Left tempo-parietal white matter region and standardized reading scores of typically developing children. Additionally, they found that fractional anisotropy values in that region accounted for differences in reading score between typically developing children and children with dyslexia children.

Turning to the role of grey matter, Altarelli et al. (2013) examined whether cortical thickness of the ventral occipitotemporal regions differed between dyslexic and typically developing children. They found a reduction in thickness in dyslexic compared with controls in the VWFA, i.e., the Left posterior OTS. In their meta-analysis, Richlan et al. (2013) found converging evidence of reduced grey matter in the bilateral superior temporal sulcus in dyslexic participants compared to typically developing controls. They also found evidence of structural and functional abnormalities in the Left occipitotemporal region in prereaders with a family history of developmental dyslexia (Richlan et al., 2013).

One limitation of the existing body of data is that it does not furnish information on the influence of early cerebral constraints on academic achievement. Indeed, nearly all studies on the relation between neuroanatomy and academic achievement have focused on structural brain characteristics, such as grey matter density or white matter tracts (Dehaene et al., 2015; Peters et al., 2018), that are affected by brain maturation and learning (e.g., Zatorre et al., 2012). To evaluate early cerebral constraints on mathematical or reading achievement, it is important to examine neuroanatomical characteristics that are not affected by brain maturation and learning. Researchers have recently turned to the study of sulcal pattern of the brain as this qualitative feature of the cortex anatomy is determined in utero (Mangin, Jouvent, \& Cachia, 2010) and is stable during development (Tissier et al., 2018). Studying brain sulcal pattern thus allows researchers to further unravel the question of causes of individual differences that are independent of learning and development.

Applying this methodology to the study of individual differences in mathematical cognition, in a recent pre-registered study (https://osf.io/w3zvc) Roell et al. (in prep) examined whether the IPS sulcal pattern explains individual differences in number processing in sample of grade 1 to grade 4 children ( $n=77$ ) and adults $(n=21)$. They characterized the Left and Right IPS sulcal pattern as "sectioned" vs "not sectioned" based on the presence or absence of branches completely sectioning the IPS using Zlatkina \& Petrides' (2014) classification. They found that IPS sulcal pattern explains part of the variance in both the children's and adult's symbolic number comparison and math fluency abilities but not in their non-symbolic number abilities. As with the data on the association between sulcal morphology and reading, it appears of importance to be able to replicate the association between the sulcal morphology of the IPS and symbolic number processing and arithmetic ability in a large sample of participants with a narrower age range.

Using the same method, Borst et al. (2016) and Cachia et al. (2017) have shown that the sulcal pattern of the OTS is associated with reading abilities. In their study, Borst et al. (2016) examined the relationship between OTS sulcal pattern and reading abilities in 8-year-old children ( $n=16$ ). They found that participants with an interrupted Left OTS had significantly better reading abilities than participants with a continuous Left OTS. Cachia et al. (2017), replicated this effect in a larger sample $(n=62)$ of adult participants and determined that this effect was specific to the posterior portion of the Left OTS, which hosts the VWFA. They also found that the length of the OTS posterior interruption was positively correlated with reading skills. It remains to be determined whether the effect found by Cachia et al. (2017) of a specific association between the posterior portion of the Left OTS and reading can also be replicated in a sufficiently large sample of children.

In addition to studies that either focus on reading or on mathematics, it would be of interest to examine potential overlap or specificity of the sulcal pattern effect of the IPS on mathematical abilities and OTS on reading. Indeed, mathematical and reading abilities have been found to be correlated (Grimm, 2008). Comorbidity or co-occurrence of specific learning disorders in reading (dyslexia) and in math (dyscalculia) is remarkably high (Peters \& Ansari, 2019). Furthermore, functional neural overlap of arithmetic and reading has been reported (Evans et al., 2016). Children with dyslexia have been reported to show atypical brain activation patterns during arithmetic in arithmetic-related regions, such as the supramarginal gyrus (Evans et al., 2014) and there is evidence to suggest that children with dyslexia and dyscalculia show highly overlapping patterns of brain activity during the processing of number (e.g., Peters et al., 2018).

\section{Research aims}

The aim of this study is threefold. For our first aim, Aim 1, we focus on the association between sulcal morphology of the IPS and individual differences in arithmetic and number processing. We wish to conceptually replicate in a larger dataset of participants in the same age range and extend our previous study (Roell et al., in prep). In continuation of Roell et al.'s study, we expect that IPS sulcal morphology explains part of the variability observed in arithmetic and symbolic number ability in typically developing children. That is, we hypothesize that children with a "sectioned" IPS will have greater symbolic number comparison and arithmetic abilities than children with a "not sectioned" IPS. In order to further our understanding of the relationship between symbolic number processing, arithmetic and the sulcal morphology of the IPS, we will extend Roell et al.'s (in prep) study by investigating whether symbolic number processing mediates the association between sulcal morphology and arithmetic. Indeed, relations between children's mathematics achievement and their basic number processing skills have been reported in both cross-sectional and longitudinal studies (De Smedt et al., 2013; Holloway \& Ansari, 2009; Schneider et al., 2017). In their longitudinal study Bartelet et al. (2014) reported that symbolic number processing was consistently a significant predictor of arithmetic achievement regardless of children's level of arithmetic proficiency. Similarly, a significant correlation between the activation in the IPS during symbolic number task and arithmetic task has been found (Bugden et al., 2012). Moreover, Roell et al. (in prep) observed an association of sulcal morphology with both number processing and arithmetic ability. As such, it would appear interesting to examine whether the relationship between IPS sulcal morphology and arithmetic ability is mediated by symbolic number processing. We hypothesize that symbolic number processing mediates the association between IPS sulcal morphology and arithmetic ability. That is, participants with a "sectioned" IPS will have greater symbolic number comparison abilities; these greater symbolic number comparison abilities will in turn be associated with greater arithmetic abilities.

Page 3/16 
Our second aim, Aim 2, is to conceptually replicate and extend the findings of Cachia et al. (2017) and Borst et al. (2016) in a large sample of children. Specifically, we shall examine whether the effect found by Cachia et al. (2017) in adults of a specific association between the posterior portion of the Left OTS and reading can also be replicated in a large sample of children. Namely, we expect that participants with an interrupted Left OTS, in particular in its posterior portion hosting the visual word form area (VWFA), will have better reading performance than participants who have a continuous Left OTS.

Our third aim, Aim 3, is to examine whether the effect of sulcal morphology on academic abilities is specific. As discussed above, studies examining behaviour, learning disorders and functional networks point towards an overlap between reading and mathematical abilities. Additionally, the specificity of the IPS for number and arithmetic processing (Fias et al., 2007) and the VWFA for reading (Vogel et al., 2014) remains controversial. As such, in view of the existing overlap, it becomes relevant to determine whether the effect of the IPS sulcal pattern on numerical abilities is specific, as well as the effect of the OTS sulcal pattern on reading is specific. The overlap and specificity of the IPS and OTS will be examined through three different analyses. Firstly, we shall test whether the sulcal pattern of IPS predicts reading and the sulcal pattern of Left posterior OTS predicts arithmetic abilities. Secondly, we shall run the same analyses as in Aim 1 and 2 but we shall add the other academic ability as a covariate. That is, we shall examine the effect of IPS sulcal morphology on mathematical ability whilst controlling for reading ability. Similarly, we shall examine the effect of OTS sulcal morphology on reading ability whilst controlling for mathematical ability. Thirdly, we shall use a third sulcal pattern, which is much less related to reading or mathematical ability, as a control region. More specifically we will examine if the sulcal morphology of the ACC (anterior cingulate cortex) is related to math and reading abilities. Studies have found that an asymmetrical ACC sulcal pattern, that is each hemisphere had a different ACC sulcal pattern, was associated with higher inhibitory control efficiency in both children (Borst et al., 2016; Cachia et al., 2017) and adults (Fornito, 2004; Huster et al., 2009; Tissier et al., 2018). Against this background, we predict that, if the association between sulcal patterns and academic achievement is specific, this sulcal pattern of the ACC will be much less related to math abilities or reading ability. Finally, we also tested whether a relationship between the sulcal pattern of the IPS and that of the OTS could be found. That is, are participants with an "interrupted" OTS more likely to have a "sectioned" IPS and vice-versa?

To address the three aims outlined above, we will utilize structural MRI data from two existing samples collected in the same age range. These structural data were previously collected for a variety of different studies (Bellon et al., 2020; Polspoel et al., 2017) and all have the same structural image scans as well as academic achievement measures (Tempo Test Arithmetic task, symbolic number comparison task, Dutch one-minute reading test). We selected behavioural measures common to all samples that measured academic achievement. It is of note that both datasets initially focused on mathematical ability. As such, the datasets contained more common mathematical tasks which allow us to also investigate the cognitive correlates of mathematical ability (through our mediation analysis) in a more fine-grained way as compared to reading ability. The functional data has already been published (Bellon et al., 2020; Polspoel et al., 2017) and forty-seven of the structural MRI (grey matter volume and DTI) data has already been published (Polspoel et al., 2019, 2020). However, no research has been conducted on the sulcal morphology data so far.

Because sex has been shown to have a potential effect on sulcal anatomy (Duchesnay et al., 2007) and because intellectual ability (IQ) has been found to be related mathematical abilities (e.g., Passolunghi et al., 2008) and reading abilities (e.g., Tiu et al., 2003), we shall account for potential effects of both sex and IQ on the relationship between sulcal morphology and academic skills. Similarly, given that we combine data from two different samples, we shall control for the potential effect of sample.

\section{Methods Participants}

Our combined dataset included participants from two separate samples comprising a total $N$ of 97 typically developing grade 4 children with a wide range of mathematical abilities. Data from both samples were all collected with the same scanner in a similar time window at KU Leuven University in Leuven, Belgium. All participants were Grade 4 children collected from communities within and around Leuven. From these samples 47 participants were drawn out from Polspoel et al. (2019) and 50 from Bellon et al. (2020). T1 MRI data that had too much movement for a clear labelling of the IPS and OTS were excluded, as were T1 MRI data that had classification disagreements (see below for more information) between the two raters. For the IPS analyses, we excluded 4 participants from Polspoel et al. (2019) and 3 from Bellon et al. (2020). Resulting in the data set of 90 (47 female) with a mean age of $9.94 \pm 0.39$ years. For the OTS analyses, we excluded 14 participants from Polpsoel et al. (2019) and 17 participants from Bellon et al. (2020). Resulting in a dataset of 66 participants (30 female) with a mean age of $9.94 \pm 0.38$ years. Informed consent was obtained from all participant's caregivers. All participants were tested in accordance with national and international norms governing the use of human research participants.

\section{Behavioral measures}

Arithmetic fluency was measured with the Tempo Test Arithmetic task (TTA, De Vos, 1992), a standardized test of arithmetical fluency similar to the Math Fluency subtest of the Woodcock-Johnson III (Woodcock et al., 2003). The test consists of five columns of arithmetic items (one column per operation and a column with mixed operations) which increase in difficulty. Each participant is given a minute per column/subtest to provide as many correct answers as possible. The score on this test combines the number of correctly solved problems on each subtest within the time limit. This test combines speed and accuracy into one index score.

A computerized assessment of number processing ability was also used, a symbolic number comparison task (e.g. Vanbinst et al., 2016). In this task, children had to compare two simultaneously presented Arabic digits, displayed on either side of a 15-inch computer screen. They had to indicate the larger one by pressing a key on the side of the larger digit. Stimuli comprised al combination of numbers 1 to 9 thus yielding a total of 72 trials. The position of the largest was counterbalanced. Each trial started with a central fixation point of $200 \mathrm{~ms}$ followed by a blank screen of $800 \mathrm{~ms}$. Thereafter stimuli appeared and 
remained visible until response. Response times and answers were registered. To familiarize children with the task, two practice trials were presented beforehand. We choose to focus on the reaction time of the participants during the single-digit symbolic number comparison task, as the accuracy of the Grade 4 participants was high, with a mean of $97.16 \pm 2.40 \%$ accuracy (see Table 1 ), thereby resulting in a ceiling effect. Additionally, in their meta-analysis Schneider et al. (2017) observed that with older participants, reaction time is the most reliable measure.

Reading ability was measured by the normed and standardized Dutch One-Minute Test (Brus \& Voeten, 1995) which is similar to the Woodcock Johnson reading fluency measure and is widely used in Flanders. For this test participants are told to correctly read aloud for 1 minute as many words as possible in the list of 116 words. The list of words consists of one up to five syllable words of increasing difficulty. Similarly to the TTA, the test combines speed and accuracy into one index score.

Intellectual ability (IQ) was assessed by either the WISC-II-NL block design (Weschsler, 2005) for the Polspoel et al. (2019) or the Raven Progressive Matrices (Raven et al., 2003) for the Bellon et al. (2020) sample. In both cases a standardized IQ scores will be used.

\section{MRI Acquisition}

Structural (T1) MRIs were acquired with a 3T Philips Ingenia CX Scanner at the Department of Radiology at the University Hospital of Leuven, Belgium. Highresolution T1-weighted anatomical images (182 slices, resolution $0.98 \times 0.98 \times 1.2 \mathrm{~mm}$, TR $=9.6 \mathrm{~ms}$ TE $=4.6 \mathrm{~ms}, 256 \times 256$ acquisition matrix) that were obtained for all participants. These MRIs are adapted for sulcus segmentation required for the three-dimensional reconstruction of the fine individual cortical folds.

\section{Sulcal morphology}

Analysis of the OTS and IPS sulcal morphology was performed using BrainVISA 4.5 software (http://brainvisa.info/ ). The sulcal patterns of the IPS and OTS were visually assessed using three-dimensional, mesh-based reconstruction of cortical folds. All MRI data were anonymized, and manual labelling of IPS and OTS in Left and Right hemispheres was carried out blind to possible confounding information, i.e. participant's age, reading, arithmetic and symbolic number comparison abilities, as well as the label of the sulcal pattern in the contralateral hemisphere. Importantly, the manual labelling of the IPS and OTS was carried out independently by two experimenters with $86.3 \%$ agreement and Cohen's kappa of .77 for the Right hemisphere and $75.5 \%$ agreement and Cohen's kappa of .65 for the Left hemisphere.

\section{IPS}

We used the protocol put forward by Roell et al. (in prep) to classify the IPS. Following the atlas by Zlatkina \& Petrides (2014), we used the Central Sulcus and the Post-Central Sulcus as landmarks to localize the horizontal segment of the IPS extending posterior to these sulci and as far as the sulcus of Brissaud and the anterior part of the paraoccipital sulcus (Zlatkina \& Petrides, 2014). This anatomical identification was cross-validated using functional information based on the mean positions of the activation coordinates for symbolic and non-symbolic number processing: $(-34 ;-48 ; 44)$ for Left IPS and (36; -46; 44) for Right IPS. These coordinates were derived from a meta-analysis of 57 studies (Sokolowski et al., 2017). Right and Left IPS sulcal pattern were then classified as "Sectioned" or "Not Sectioned" based on the presence or absence of branches completely sectioning the IPS (see Fig. 1).

\section{OTS}

For the characterization of the OTS, we used exactly the same the protocol put forward by Cachia and colleagues (2017). The sulcal pattern of the Left and Right OTS was characterized as "interrupted" when the OTS has interruptions and "continuous" otherwise. In addition, to investigate the possible effect of the position of the OTS interruption, we identified whether the OTS interruption is located in the posterior part of the sulcus, host of the Visual Word Form Area in the Left hemisphere (e.g., Dehaene \& Cohen, 2011), or in the anterior part of the sulcus (see Fig. 2). We used an anatomical criterion, namely the Y-coordinate of the posterior extremity of the brainstem as a limit to define the anterior and posterior interruptions of the OTS. The functional validity of this anatomical criterion has been already established (Cachia et al., 2017).

\section{ACC}

We followed the protocol elaborated by Cachia and colleagues (Borst et al., 2014; Cachia et al., 2014, 2016; Tissier et al., 2018) to classify the ACC. The ACC sulcal pattern was categorized in two types: "single type" or "double parallel type" (Ono et al., 1990) depending on the absence or presence of a paracingulate sulcus (PCS), which is a variable secondary sulcus (Paus et al., 1996), see Fig. 3 . The PCS was defined as located dorsal to the cingulate sulcus with a course clearly parallel to the cingulate sulcus (Paus et al., 1996; Yucel et al., 2001). To reduce ambiguity from the confluence of the PCS and the cingulate sulcus with the superior rostral sulcus, we determined the anterior limit of the PCS as the point at which the sulcus extends posteriorly from an imaginary vertical line running perpendicular to the line passing through the anterior and posterior commissures (AC-PC; Yucel et al., 2001). The PCS was considered absent if there was no clearly developed horizontal sulcal element parallel to the cingulate sulcus and extending at least 20 mm (interruptions or gaps in the PCS course will not be taken into account for the length measure). PCS length was measured in a standard (MNI) space.

\section{Analysis}


A statistical analysis plan for this study was preregistered on the Open Science Framework (https://osf.io/cqsu9). Analyses were performed using the R ( $R$ Core Team, 2013) and JASP software (JASP Team, 2020). For each of the analyses, we reported effect size in terms of Cohen's $d$ for $t$-tests and eta-square for ANOVAs. Bayesian analysis were also used to quantify the evidence against $\left(\mathrm{BF}_{10}\right)$ or for $\left(\mathrm{BF}_{01}\right)$ the null hypothesis.

Before conducting analyses relevant to the 3 aims, we first assessed whether sex and IQ were associated with the academic measures. If associations were found to be significant, we included these variables as covariates in the regression models. We also assessed whether there was any database difference in the academic measures. If database differences were found to be significant, we included database as a covariate in the regression model.

\section{Aim 1: Associations between number/arithmetic and IPS sulcal morphology}

For our first aim, we determined whether the sulcal patterns of the Right and Left IPS were associated with the participant's symbolic number processing abilities and arithmetic abilities.

We first assessed the relationship between IPS sulcal pattern (Left and Right IPS) and symbolic number processing as well as the arithmetic through $t$-tests. If an association was found between number/arithmetic and IPS sulcal pattern, subsequent regressions tested whether the association holds when the abovementioned covariates (IQ, sex and database) are included.

Finally, we assessed whether participants' scores in the TTA task were correlated with the symbolic number comparison task. If these were indeed correlated and we find an association between IPS and arithmetic abilities, we ran a mediation model, to examine whether symbolic number processing mediates the relationship between IPS sulcal morphology and arithmetic ability. We hypothesized a direct effect between IPS sulcal pattern and arithmetic ability as well as an indirect effect between IPS sulcal pattern and arithmetic ability through symbolic number abilities, see Fig. 4.

\section{Aim 2: Associations between reading and sulcal morphology OTS}

For our second aim, we strived to replicate the results found by Borst et al. (2016) and Cachia et al. (2017). To do so, we first assessed the relationship between OTS sulcal pattern (Left posterior OTS, Left anterior OTS, Right posterior OTS and Right anterior OTS) and reading through $t$-tests. If an association was found between reading and OTS sulcal pattern, subsequent regressions examined whether the association holds when the abovementioned covariates are included.

If we found that participants with interrupted Left posterior OTS had better reading skills than participants with a continuous Left posterior OTS, we then examined whether we may find a positive correlation between the length of the interruption and reading ability as was found in (Cachia et al., 2017).

\section{Aim 3: Overlap and specificity of sulcal morphology related to mathematics and reading}

Three analyses were performed to evaluate the specificity of the effect of the IPS sulcal pattern on mathematical abilities and of the specificity of the effect of the OTS sulcal pattern on reading abilities. Firstly, we investigated whether the sulcal pattern of the IPS might be related to reading ability and whether the sulcal pattern of the OTS might be related to mathematical ability via $t$-tests. Secondly, we tested whether the association between IPS sulcal pattern and mathematical ability remains when reading ability is controlled for. Likewise, we examined whether the association between OTS sulcal pattern and reading ability remains when mathematical ability is controlled for. Thirdly, we examined whether mathematical and reading ability are associated to the sulcal pattern of the ACC, a sulcus unrelated to both academic skills. To do so, we investigated whether ACC pattern groups ("single type" vs "double parallel type") differ in their mathematical and reading ability. Finally, we also tested whether a relationship between the sulcal pattern of the IPS and that of the OTS could be found. That is, are participants with an "interrupted" OTS more likely to have a "sectioned" IPS and vice-versa.

\section{Results}

\section{General description}

We first explored the data for potential outliers, defined as values larger or smaller than one and a half times the interquartile range. Four outliers were identified and excluded in the symbolic number measure. In the arithmetic measure, one outlier was identified and excluded. In the reading measure, two outliers were identified and excluded. Notably, our data was analyzed both with and without the outliers, including the outliers did not affect the results.

We then analyzed whether sex and IQ were associated with arithmetic, symbolic number and reading abilities. Sex was not found to be associated with arithmetic abilities, $t(87)=-1.65, p=.10$, Bayesian analysis weakly supported the null hypothesis (Jarosz \& Wiley, 2014), $\mathrm{BF}_{01}=1.37$. Nor was sex associated with symbolic number abilities, $t(83.62)=0.73, p=.46$, and the evidence for this absence of an association was weak $B F_{01}=1.94$. Similarly, sex was not found to be associated with reading, $t(62)=0.01, p=.98$, and the evidence for this absence of an association was substantial $B F_{01}=3.91$. IQ was not correlated with arithmetic ability, $r(87)=.10, p=.30$, symbolic number abilities $r(84)=-.05, p=.64$, or reading, $r(62)=.03, p=.78$. Additionally, Bayesian analysis substantially supports the null hypothesis (Jarosz \& Wiley, 2014) for IQ and arithmetic, $\mathrm{BF}_{01}=4.53$, IQ and symbolic number abilities, $B F_{01}=6.67$, and for IQ and reading, $\mathrm{BF}_{01}=6.18$. To conclude, neither sex nor IQ were associated with the academic skills measured in this study, and therefore they were not included as covariates in the subsequent models. 
We also analyzed whether there were any database differences in arithmetic, symbolic number comparison and reading abilities (see Table 1). No database differences were found in arithmetic abilities, $t(87)=0.26, p=.79$, and the evidence for this absence of an association was substantial $\mathrm{BF}_{01}=4.37$. No database differences were found in symbolic number comparison abilities, $t(84)=0.61, p=.53$, and the evidence for this absence of an association was substantial $\mathrm{BF}_{01}=3.76$. No database differences were found in reading abilities, $t(62)=0.62, p=.52$, and the evidence for this absence of an association was substantial $\mathrm{BF}_{01}=3.29$. Since we did not find any database differences in the academic measures, we did not include database as a covariate in the subsequent models.

Table 1

Descriptive information of the academic measures and IQ according to database.

\begin{tabular}{|c|c|c|c|c|c|c|}
\hline & & $\begin{array}{l}\text { Arithmetic } \\
\text { ability }\end{array}$ & $\begin{array}{l}\text { Symbolic number ability } \\
\text { (Reaction time) }\end{array}$ & $\begin{array}{l}\text { Symbolic number ability } \\
\text { (Accuracy) }\end{array}$ & $\begin{array}{l}\text { Reading } \\
\text { ability }\end{array}$ & $\begin{array}{l}\text { IQ (WISC-II or } \\
\text { Raven) }\end{array}$ \\
\hline \multirow{4}{*}{$\begin{array}{l}\text { Polspoel et al. } \\
\text { (2019) }\end{array}$} & M & 100.6 & 778.3 & 98.1 & 61.8 & 44.2 \\
\hline & SD & 16.9 & 123.5 & 1.9 & 10.5 & 10.7 \\
\hline & Minimum & 73.0 & 567.7 & 93.1 & 39.0 & 24.0 \\
\hline & Maximum & 136.0 & 1058.89 & 100.0 & 90.0 & 69.0 \\
\hline \multirow{4}{*}{$\begin{array}{l}\text { Bellon et al. } \\
(2020)\end{array}$} & $M$ & 99.6 & 761.6 & 96.2 & 60.0 & 36.4 \\
\hline & SD & 19.1 & 127.3 & 2.5 & 11.9 & 7.8 \\
\hline & Minimum & 65.0 & 561.9 & 91.7 & 37.0 & 14.0 \\
\hline & Maximum & 142.0 & 1088.42 & 100.0 & 87 & 49.0 \\
\hline \multirow[t]{4}{*}{ Both databases } & M & 100.1 & 769.5 & 97.2 & 60.9 & 40.1 \\
\hline & SD & 17.9 & 125.0 & 2.4 & 11.2 & 10.0 \\
\hline & Minimum & 65.0 & 562.0 & 91.7 & 37.0 & 14.0 \\
\hline & Maximum & 142.0 & 1077.4 & 100 & 90.0 & 69.0 \\
\hline
\end{tabular}

We also examined the distribution of sulcal patterns of the IPS (Table 2), OTS ( Table 3) and ACC ( Table 4).

Table 2

Distribution of participants with "Sectioned" or "Not sectioned" Left and Right IPS

\begin{tabular}{|lll|}
\hline & Left IPS & Right IPS \\
\hline Sectioned & 32 & 40 \\
\hline Not sectioned & 58 & 50 \\
\hline
\end{tabular}

Table 3

Distribution of participants with an "Interrupted" or "Continuous" Left posterior, Left anterior, Right posterior and Right anterior OTS

\begin{tabular}{|lllll|}
\hline & Left Posterior OTS & Left Anterior OTS & Right Posterior OTS & Right Anterior OTS \\
\hline Interrupted & 21 & 10 & 21 & 22 \\
\hline Continuous & 45 & 56 & 45 & 44 \\
\hline
\end{tabular}

Table 4

Distribution of participants with a "Single type" or a "Double type" Left and Right

\begin{tabular}{|lll|}
\hline & Left ACC & Right ACC \\
\hline Single type & 32 & 54 \\
\hline Double type & 58 & 36 \\
\hline
\end{tabular}




\section{Aim 1: Associations between number/arithmetic and IPS sulcal morphology}

We first examined whether the sulcal pattern of the Left and Right IPS was associated with arithmetic abilities. There was no association between Left IPS and arithmetic, $t(87)=1.63, p=.10$, and the evidence for this absence of an association was weak $\mathrm{BF}_{01}=1.35$, see Fig. 5 . Similarly no association between Right IPS and arithmetic was found, $t(87)=1.32, p=.18$, and the evidence for this absence of an association was weak $B F_{01}=2.07$, see Fig. 5 .

We then analyzed whether the sulcal pattern of the Left and Right IPS was associated with symbolic number ability. The Left IPS was not found to be significantly associated with symbolic number abilities, $t<1$, and the evidence for this absence of an association was substantial $\mathrm{BF} 01=4.18$. Contrastingly, Right IPS was found to be significantly associated with symbolic number ability, $t(84)=-2.07, p=.04$, and the evidence for this association was weak $\mathrm{BF}_{10}=$ 1.44. Participants with a sectioned Right IPS had significantly longer reaction times in the symbolic number comparison task than participants with a not sectioned IPS, see Fig. 6.

Next, we assessed whether participants' scores in the arithmetic task are correlated with the symbolic number comparison task. Arithmetic ability was found to be correlated with symbolic number ability, $r(83)=-0.35, p<.001$ and the evidence for this association was very strong with $\mathrm{BF}_{10}=44.70$. Although arithmetic ability and symbolic number ability are indeed correlated, we did not find an association between IPS and mathematical abilities (arithmetic and symbolic ability). As such, it was not appropriate to conduct mediation analyses examining whether symbolic number processing mediates the relationship between IPS sulcal morphology and arithmetic ability (but see Supplementary Sect. 1 for mediation analyses).

\section{Aim 2: Associations between reading and sulcal morphology OTS}

The Left posterior and anterior OTS were not found to be significantly associated with reading ability, $t(1,62)=1.69, p=.09$, and $t<1$, respectively, see Fig. 7 . The evidence for this association was weak for both the Left posterior, $\mathrm{BF} 01=1.14$ and Left anterior OTS, $\mathrm{BF}_{01}=2.49$. Similarly, the Right posterior OTS was not found to be significantly associated with reading ability, $t<1$ (see Fig. 7) and the evidence for this absence of an association was weak $B F_{01}=2.58$. The Right anterior OTS was found to be moderately associated with reading ability with $t(1,62)=-2.03, p=.05$ (see Fig. 7 ), the evidence for this association was weak $\mathrm{BF}_{10}=1.47$.

\section{Aim 3: Overlap and specificity of sulcal morphology related to mathematics and reading}

Our third aim was to examine the specificity of the effect of the IPS sulcal pattern on numerical abilities as well as the specificity of the effect of the OTS sulcal pattern on reading. However, this study failed to find a clear effect of the IPS sulcal pattern on arithmetic and symbolic number comparison abilities, nor did the study find a clear effect of the OTS sulcal pattern on reading abilities. As such, it seemed ill-guided to study the specificity of both these effects (but see Supplementary Sect. 2 for the results of the analyses of Aim 3).

\section{Discussion}

The present study sought to investigate the impact of neuroanatomical constraints on key academic abilities, namely mathematical and reading ability. We examined a specific neuroanatomical characteristic that is not affected by brain maturation and learning, sulcal patterns of the brain (Cachia et al., 2016; Mangin et al., 2010). Specifically, we focused on the sulcal pattern of the IPS and the OTS as both regions have consistently been associated with mathematical processes and reading respectively (Dehaene \& Cohen, 2011; Menon, 2014; Peters \& De Smedt, 2018). Through this approach we wished to gain some insight as to biological constraints that influence the development of reading and mathematics.

The first aim focused on the relationship between the IPS sulcal pattern and mathematical ability. We hypothesized in accordance with Roell et al.'s (in prep) findings, that IPS sulcal morphology would explain part of the the variability observed in symbolic number comparison and arithmetic tasks in typically developing children. In contrast to our expectations, no significant association between arithmetic ability and IPS sulcal morphology (Left and Right) were found. A significant association was found between the Right IPS sulcal morphology and symbolic number abilities. However, this association was the opposite to what we had hypothesized and what Roell et al. (in prep) found. We found that participants with a "sectioned" Right IPS had worse symbolic number abilities, here reaction time, than participants with a "not sectioned" Right IPS. Importantly, we were able to replicate the well-know association between symbolic number ability and arithmetic ability, hereby assuring the validity of both measures.

The second aim of this study centered on the relationship between OTS sulcal pattern and reading ability. We expected that in line with the findings of Cachia et al. (2017) and Borst et al. (2016), participants with an interrupted Left posterior OTS, in particular in its posterior portion hosting the visual word form area (VWFA), will have better reading performance than participants who have a continuous Left OTS. In contrast to our expectations, we did not find such an effect.

Our third aim was to examine the specificity of the effect of the IPS sulcal pattern on numerical abilities as well as the specificity of the effect of the OTS sulcal pattern on reading. However, since we were unable to find an effect of either the IPS sulcal pattern in numerical abilities nor of the OTS sulcal pattern on reading abilities, we did not pursue such aim.

The present study was unable to replicate a previously observed relationship between the IPS sulcal pattern and mathematical ability Roell et al., (in prep), and a previously observed association between the Left posterior OTS sulcal pattern and reading (Borst et al., 2016; Cachia et al., 2017). It is unlikely that the lack of findings is due to our methods. Indeed, we followed the protocol for labelling the IPS (Roell et al., in prep) and the 0TS (Borst et al., 2016; Cachia et al.,

Page 8/16 
2017) extremely closely. Our inter-rater reliability was relatively high at $80.59 \%$. In addition, the academic measures used did not differ from the ones used in previous research. The symbolic number comparison measure and the arithmetic ability measure are very similar to the ones used in Roell et al.'s (in prep) study. The Dutch one-minute test is extremely similar to the test used by both Cachia et al. (2017) and Borst et al. (2016) in their studies, as it also relies on the number of words read correctly aloud in a given time. Additionally, this measure is a very reliable reading measure and has been widely used in research.

The lack of findings might be due to the fact that the sample in this study might have been too homogenous in terms of its academic performance. All participants came from the same grade and they were from fairly high socio-economic backgrounds. As such, it may be that the performance in the math and reading task may not have been varied enough. It may be that there lacked enough variability in the academic measures to be explained by the OTS and IPS sulcal measures. Past studies have selected specific samples that were more varied in their performance. Cachia et al.'s (2017) sample consisted of participants that learnt to read as children and participants that had learnt to read as adults, thereby assuring a great variability in reading ability. In addition, the participants' background was extremely diverse with participants from both low and high socio-economical backgrounds. In Roell et al.'s (in prep) study, variability in mathematical ability was assured through a sample age range, as participants in the children group range from Grade 1 to Grade 4 . On the other hand, although by selecting heterogeneous samples the previous studies have been able to measure variability in the academic skills, the findings might have been confounded by age and SES differences in the sample rather than real differences in the association between academic skills and sulcal morphology. Future studies should examine specifically the possible effect of age and SES differences on the relationship between sulcal morphology and academic abilities.

It may also be that there was an effect of sulcal morphology, but it was too subtle for us to pick up. Indeed, the Bayesian effects observed were all predominantly small thus pointing towards anecdotal or weak evidence. Which would mean that either the effects of sulcal morphology on academic achievements are not there or are too small and a much larger samples are needed to pick them up. Currently the data presented here cannot unravel this point, a study with a larger sample would be needed. Note that our sample was sufficiently powered to detect a medium effect size $(\mathrm{d}=.30$, power $=.86)$, it was not for detecting small effects $(d=.10$, power $=.17)$.

Although we followed extremely closely the protocols elaborated by Borst et al. (2016), Cachia et al. (2017) and Roell et al. (in prep), we were not able to replicate their results. Another possible explanation for the lack replication is the country-based and language-based educational differences. As mentioned above, children in Flemish school have notably high math fluency whereas children from Roell et al.'s (in prep) study came from Ontario (Canada). Importantly, children from Ontario (Canada) have significantly lower than average math fluency levels (Archibald et al., 2013). Future studies should examine the potential effect of language and educational differences on the relationship between sulcal morphology and academic abilities.

In conclusion, our study was unable to find a relationship between the IPS sulcal pattern and mathematical ability, nor did we observe an effect of the Left posterior OTS sulcal pattern on reading. It might be that such effects are only observable in heterogenous samples (as in previous work). On the other hand, it might be explained by differences in background and the education of the sample as compared to previous work. Future studies might want to explore this effect further by conducting a study with samples from different countries with different educational levels.

\section{Declarations}

\section{Funding}

Margot Roell and Elien Bellon are both supported by the Postdoctoral Mandate (PDM) under the Katholieke Universiteit Leuven program.

\section{Conflicts of interest}

The authors declare that they have no conflict of interest.

\section{Availability of data and materials}

Not applicable

\section{Code availability}

Not applicable

\section{Ethical approval}

The study was approved by the Social and Societal Ethics Committee of the KU Leuven.

\section{Informed consent}

Written informed consent was obtained from each subject prior to testing 


\section{Consent for publication}

Participants provided written informed consent for the publication of any associated data.

\section{References}

1. Altarelli,I,Monzalvo,K.,Iannuzzi,S.,Fluss,J.,Billard,C.,Ramus,F.,\&Dehaene-Lambertz,G.(2013).A Functionally Guided Approach to the Morphometry of Occipitotemporal Regions in Developmental Dyslexia: Evidence for Differential Effects in Boys and Girls.Journal of Neuroscience,33(27),1129611301.https://doi.org/10.1523/JNEUROSCI.5854-12.2013

2. American Psychiatric Association.(2013).Diagnostic and statistical manual of mental disorders (DSM-5®).American Psychiatric Pub.

3. Ansari,D.(2008).Effects of development and enculturation on number representation in the brain.Nature Reviews Neuroscience,9(4),278291.https://doi.org/10.1038/nrn2334

4. Archibald,L. M. D.,Cardy,J. O.,Joanisse,M. F.,\&Ansari,D.(2013).Language, Reading, and Math Learning Profiles in an Epidemiological Sample of School Age Children.PLOS ONE,8(10),13.

5. Arsalidou,M.,\&Taylor,M. J.(2011).Is $2+2=4$ ? Meta-analyses of brain areas needed for numbers and calculations.Neurolmage,54(3),23822393.https://doi.org/10.1016/j.neuroimage.2010.10.009

6. Bartelet,D.,Vaessen,A.,Blomert,L.,\&Ansari,D.(2014).What basic number processing measures in kindergarten explain unique variability in first-grade arithmetic proficiency? Journal of Experimental Child Psychology,117,12-28.https://doi.org/10.1016/j.jecp.2013.08.010

7. Bellon,E.,Fias,W.,Ansari,D.,\&DeSmedt,B.(2020).The neural basis of metacognitive monitoring during arithmetic in the developing brain.Human Brain Mapping,41(16),4562-4573.https://doi.org/10.1002/hbm.25142

8. Bolger,D. J.,Perfetti,C. A.,\&Schneider,W.(2005).Cross-cultural effect on the brain revisited: Universal structures plus writing system variation.Human Brain Mapping,25(1),92-104.https://doi.org/10.1002/hbm.20124

9. Borst,G.,Cachia,A.,Tissier,C.,Ahr,E.,Simon,G.,\&Houdé,O.(2016).Early cerebral constraints on reading skills in school-age children: An MRI study.Mind, Brain, and Education,10(1),47-54.

10. Borst,G.,Cachia,A.,Vidal,J.,Simon,G.,Fischer,C.,Pineau,A.,Poirel,N.,Mangin,J.-F.,\&Houdé,O.(2014).Folding of the anterior cingulate cortex partially explains inhibitory control during childhood: A longitudinal study.Developmental Cognitive Neuroscience,9,126-135.https://doi.org/10.1016/j.dcn.2014.02.006

11. Bugden,S.,Price,G. R.,McLean,D. A.,\&Ansari,D.(2012).The role of the Left intraparietal sulcus in the relationship between symbolic number processing and children's arithmetic competence.Developmental Cognitive Neuroscience,2(4),448-457.https://doi.org/10.1016/j.dcn.2012.04.001

12. Cachia,A.,Borst,G.,Tissier,C.,Fisher,C.,Plaze,M.,Gay,O.,Rivière,D.,Gogtay,N.,Giedd,J.,Mangin,J.-F.,Houdé,O.,\&Raznahan,A.(2016).Longitudinal stability of the folding pattern of the anterior cingulate cortex during development.Developmental Cognitive Neuroscience,19,122-

127.https://doi.org/10.1016/j.dcn.2016.02.011

13. Cachia,A.,Borst,G.,Vidal,J.,Fischer,C.,Pineau,A.,Mangin,J.-F.,\&Houdé,O.(2014).The Shape of the ACC Contributes to Cognitive Control Efficiency in Preschoolers.Journal of Cognitive Neuroscience,26(1),96-106.https://doi.org/10.1162/jocn_a_00459

14. Cachia,A.,Roell,M.,Mangin,J.-F.,Sun,Z. Y.,Jobert,A.,Braga,L.,Houde,O.,Dehaene,S.,\&Borst,G.(2017).How interindividual differences in brain anatomy shape reading accuracy.Brain Structure and Function.https://doi.org/10.1007/s00429-017-1516-X

15. Cao,F.,Bitan,T.,Chou,T.-L.,Burman,D. D.,\&Booth,J. R.(2006).Deficient orthographic and phonological representations in children with dyslexia revealed by brain activation patterns.Journal of Child Psychology and Psychiatry,47(10),1041-1050.https://doi.org/10.1111/j.1469-7610.2006.01684.x

16. Cohen,L.,Lehéricy,S.,Chochon,F.,Lemer,C.,Rivaud,S.,\&Dehaene,S.(2002).Language-specifc tuning of visual cortex? Functional properties of the Visual Word Form Area.Brain,125,16.

17. DeSmedt,B.,Holloway,I. D.,\&Ansari,D.(2011).Effects of problem size and arithmetic operation on brain activation during calculation in children with varying levels of arithmetical fluency.Neurolmage,57(3),771-781.https://doi.org/10.1016/j.neuroimage.2010.12.037

18. DeSmedt,B.,Noël,M.-P.,Gilmore,C.,\&Ansari,D.(2013).How do symbolic and non-symbolic numerical magnitude processing skills relate to individual differences in children's mathematical skills? A review of evidence from brain and behavior.Trends in Neuroscience and Education,2(2),48-

55.https://doi.org/10.1016/j.tine.2013.06.001

19. DeVosT(1992):Tempo-Test-Rekenen.Nijmegen, The Netherlands:Berkhout.

20. Dehaene,S.,\&Cohen,L.(2011).The unique role of the visual word form area in reading.Trends in Cognitive Sciences,15(6),254262.https://doi.org/10.1016/j.tics.2011.04.003

21. Dehaene,S.,Cohen,L.,Morais,J.,\&Kolinsky,R.(2015).Illiterate to literate: Behavioural and cerebral changes induced by reading acquisition.Nature Reviews Neuroscience,16(4),234-244.https://doi.org/10.1038/nrn3924

22. Dehaene-Lambertz,G.,Monzalvo,K.,\&Dehaene,S.(2018).The emergence of the visual word form: Longitudinal evolution of category-specific ventral visual areas during reading acquisition.PLOS Biology,16(3),e2004103.https://doi.org/10.1371/journal.pbio.2004103

23. Demir-Lira,Ö. E.,Prado,J.,\&Booth,J. R.

(2016).NeuralCorrelatesofMathGainsVaryDependingonParentalSocioeconomicStatus(SES).FrontiersinPsychology,7.https://doi.org/10.3389/fpsyg.2016.0

24. Downing,P. E.,Chan,A. W.-Y.,Peelen,M. V.,Dodds,C. M.,\&Kanwisher,N.(2006).Domain Specificity in Visual Cortex.Cerebral Cortex,16(10),1453-

1461.https://doi.org/10.1093/cercor/bhj086

Page $10 / 16$ 
25. Duchesnay,E.,Cachia,A.,Roche,A.,Riviere,D.,Cointepas,Y.,Papadopoulos-Orfanos,D.,Zilbovicius,M.,Martinot,J.-L.,Regis,J.,\&Mangin,J.-F.(2007).Classification Based on Cortical Folding Patterns.IEEE Transactions on Medical Imaging,26(4),553-565.https://doi.org/10.1109/TMI.2007.892501

26. Eger,E.,Sterzer,P.,Russ,M. O.,Giraud,A.-L.,\&Kleinschmidt,A.(2003).A Supramodal Number Representation in Human Intraparietal Cortex.Neuron,37(4),719726.https://doi.org/10.1016/S0896-6273(03)00036-9

27. Evans,T. M.,Flowers,D. L.,Luetje,M. M.,Napoliello,E.,\&Eden,G. F.(2016).Functional neuroanatomy of arithmetic and word reading and its relationship to age.Neurolmage,143,304-315.https://doi.org/10.1016/j.neuroimage.2016.08.048

28. Evans,T. M.,Flowers,D. L.,Napoliello,E. M.,Olulade,O. A.,\&Eden,G. F.(2014).The functional anatomy of single-digit arithmetic in children with developmental dyslexia.Neurolmage,101,644-652.https://doi.org/10.1016/j.neuroimage.2014.07.028

29. Evans,T. M.,Kochalka,J.,Ngoon,T. J.,Wu,S. S.,Qin,S.,Battista,C.,\&Menon,V.(2015).Brain Structural Integrity and Intrinsic Functional Connectivity Forecast 6 Year Longitudinal Growth in Children's Numerical Abilities. The Journal of Neuroscience,35(33),11743-11750.https://doi.org/10.1523/JNEUROSCl.021615.2015

30. Fias,W.Lammertyn,J.,Caessens,B.,\&Orban,G. A.(2007).Processing of Abstract Ordinal Knowledge in the Horizontal Segment of the Intraparietal Sulcus.Journal of Neuroscience,27(33),8952-8956.https://doi.org/10.1523/JNEUROSCI.2076-07.2007

31. Fias,Wim,Lammertyn,J.,Reynvoet,B.,Dupont,P.,\&Orban,G. A.(2003).Parietal representation of symbolic and nonsymbolic magnitude.Journal of Cognitive Neuroscience,15(1),47-56.

32. Fornito,A.(2004).Individual Differences in Anterior Cingulate/Paracingulate Morphology Are Related to Executive Functions in Healthy Males.Cerebral Cortex,14(4),424-431.https://doi.org/10.1093/cercor/bhh004

33. Grimm,K. J.(2008).Longitudinal Associations Between Reading and Mathematics Achievement.Developmental Neuropsychology,33(3),410426.https://doi.org/10.1080/87565640801982486

34. Holloway,I. D.,\&Ansari,D.(2009).Mapping numerical magnitudes onto symbols: The numerical distance effect and individual differences in children's mathematics achievement.Journal of Experimental Child Psychology,103(1),17-29.https://doi.org/10.1016/j.jecp.2008.04.001

35. Holloway,I. D.,\&Ansari,D.(2010).Developmental specialization in the Right intraparietal sulcus for the abstract representation of numerical magnitude.Journal of Cognitive Neuroscience,22(11),2627-2637.

36. Huster,R. J.,Wolters,C.,Wollbrink,A.,Schweiger,E.,Wittling,W.,Pantev,C.,\&Junghofer,M.(2009).Effects of anterior cingulate fissurization on cognitive control during stroop interference.Human Brain Mapping,30(4),1279-1289.https://doi.org/10.1002/hbm.20594

37. Isaacs,E.,Edmonds,J.,Lucas,A.,\&Gadian,D.(2001).Calculation difficulties in children of very low birthweight: A neural correlate.Brain,124,1701-1707.

38. Jarosz,A. F.\&Wiley,J.(2014).What Are the Odds? A Practical Guide to Computing and Reporting Bayes Factors. The Journal of Problem Solving,7(1).https://doi.org/10.7771/1932-6246.1167

39. JASP Team(2020).JASP(Version0.14.1).

40. Kazui,H.,Kitagaki,H.,\&Mori,E.(2000).Cortical activation during retrieval of arithmetical facts and actual calculation: A functional magnetic resonance imaging study.Psychiatry and Clinical Neurosciences,54(4),479-485.https://doi.org/10.1046/j.1440-1819.2000.00739.x

41. Mangin,J.-F.,Jouvent,E.,\&Cachia,A.(2010).In-vivo measurement of cortical morphology: Means and meanings:Current Opinion in Neurology, 1.https://doi.org/10.1097/WCo.0b013e32833a0afc

42. Matejko,A. A.,Price,G. R.,Mazzocco,M. M. M.,\&Ansari,D.(2013).Individual differences in Left parietal white matter predict math scores on the Preliminary Scholastic Aptitude Test.Neurolmage,66,604-610.https://doi.org/10.1016/j.neuroimage.2012.10.045

43. Menon, V.

(2014).ArithmeticintheChildandAdultBrain(R.CohenKadosh\&A.Dowker,Eds.;Vol.1).OxfordUniversityPress.https://doi.org/10.1093/oxfordhb/978019964234

44. Mussolin,C.,DeVolder,A.,Grandin,C.,Schlögel,X.,Nassogne,M.-C.,\&Noël,M.-P.(2010).Neural Correlates of Symbolic Number Comparison in Developmental Dyscalculia.Journal of Cognitive Neuroscience,22(5),860-874.https://doi.org/10.1162/jocn.2009.21237

45. Myers,C. A.,Vandermosten,M.,Farris,E. A.,Hancock,R.,Gimenez,P.,Black,J. M.,Casto,B.,Drahos,M.,Tumber,M.,Hendren,R. L.,Hulme,C.,\&Hoeft,F. (2014).WhiteMatterMorphometricChangesUniquelyPredictChildren'sReadingAcquisition.14.

46. Navas-Sánchez,F. J.,Alemán-Gómez,Y.,Sánchez-Gonzalez,J.,Guzmán-De-Villoria,J. A.,Franco,C.,Robles,O.,Arango,C.,\&Desco,M.(2014).White matter microstructure correlates of mathematical giftedness and intelligence quotient: White Matter Microstructure.Human Brain Mapping,35(6),26192631.https://doi.org/10.1002/hbm.22355

47. Niogi,S. N.,\&McCandliss,B. D.(2006).Leftlateralizedwhitemattermicrostructureaccountsforindividualdifferencesinreadingabilityanddisability.11.

48. OECD.(2019).PISA2018Results:Combinedexecutivesummaries.

49. OnoM,KubikS,AbernatheyCD(1990)Atlas of the cerebral sulci.Stuttgart:Thieme

50. Parsons,S.,\&Bynner,J.(2005).Does Numeracy matter more?National Research and Development Center for Adult Literacy and Numeracy.

51. Passolunghi,M. C.,Mammarella,I. C.,\&Altoè,G.(2008).Cognitive Abilities as Precursors of the Early Acquisition of Mathematical Skills During First Through Second Grades.Developmental Neuropsychology,33(3),229-250.https://doi.org/10.1080/87565640801982320

52. Paus,T.,Tomaiuolo,F.,Otaky,N.,MacDonald,D.,Petrides,M.,Atlas,J.,Morris,R.,\&Evans,A. C.(1996).Human Cingulate and Paracingulate Sulci: Pattern, Variability, Asymmetry, and Probabilistic Map.Cerebral Cortex,6(2),207-214.https://doi.org/10.1093/cercor/6.2.207

53. Peters,L.,\&Ansari,D.(2019).Are specific learning disorders truly specific, and are they disorders?Trends in Neuroscience and Education,17,100115.https://doi.org/10.1016/j.tine.2019.100115

Page $11 / 16$ 
54. Peters,L.,Bulthé,J.,Daniels,N.,OpdeBeeck,H.,\&DeSmedt,B.(2018).Dyscalculia and dyslexia: Different behavioral, yet similar brain activity profiles during arithmetic.Neurolmage: Clinical,18,663-674.https://doi.org/10.1016/j.nicl.2018.03.003

55. Peters,L.,\&DeSmedt,B.(2018).Arithmetic in the developing brain: A review of brain imaging studies.Developmental Cognitive Neuroscience,30,265279.https://doi.org/10.1016/j.dcn.2017.05.002

56. Polspoel,B.,Peters,L.,Vandermosten,M.,\&DeSmedt,B.(2017).Strategy over operation: Neural activation in subtraction and multiplication during fact retrieval and procedural strategy use in children: Brain Activity in Children's Arithmetic Strategies.Human Brain Mapping,38(9),4657-

4670.https://doi.org/10.1002/hbm.23691

57. Polspoel,B.,Vandermosten,M.,\&DeSmedt,B.(2019).Relating individual differences in white matter pathways to children's arithmetic fluency: A spherical deconvolution study.Brain Structure and Function,224(1),337-350.https://doi.org/10.1007/s00429-018-1770-6

58. Polspoel,B.,Vandermosten,M.\&DeSmedt,B.(2020).The association of grey matter volume and cortical complexity with individual differences in children's arithmetic fluency.Neuropsychologia,137,107293.https://doi.org/10.1016/j.neuropsychologia.2019.107293

59. Prado,J.,Mutreja,R.,Zhang,H.,Mehta,R.,Desroches,A. S.,Minas,J. E.,\&Booth,J. R.(2011).Distinct representations of subtraction and multiplication in the neural systems for numerosity and language.Human Brain Mapping,32(11),1932-1947.https://doi.org/10.1002/hbm.21159

60. Price,G. R.,Mazzocco,M. M. M.,\&Ansari,D.(2013).Why Mental Arithmetic Counts: Brain Activation during Single Digit Arithmetic Predicts High School Math Scores.Journal of Neuroscience,33(1),156-163.https://doi.org/10.1523/JNEUROSCI.2936-12.2013

61. Price,Gavin R.,Holloway,I. D.,Räsänen,P.,Vesterinen,M.,\&Ansari,D.

(2007).Impairedparietalmagnitudeprocessingindevelopmentaldyscalculia.CurrentBiology, 17.

62. Price,Gavin R.,Wilkey,E. D.,Yeo,D. J.,\&Cutting,L. E.(2016).The relation between 1 st grade grey matter volume and 2nd grade math competence.Neurolmage,124,232-237.https://doi.org/10.1016/j.neuroimage.2015.08.046

63. R Core Team(2013).R:Alanguageandenvironmentforstatisticalcomputing.RFoundationforStatisticalComputing,Vienna,Austria.URLhttp://www.Rproject.org/.

64. Raven,J.,Raven,J.C.,\&Court,J.H.(2003).Manual for Raven's Progressive Matrices and Vocabulary Scales. Section 1: General Overview.San Antonio, TX:Harcourt Assessment.

65. Richlan,F.,Kronbichler,M.\&Wimmer,H.(2013).Structural abnormalities in the dyslexic brain: A meta-analysis of voxel-based morphometry studies.Human Brain Mapping,3065,11.

66. Rivera,S. M.,Reiss,A. L.,Eckert,M. A.,\&Menon,V.(2005).Developmental Changes in Mental Arithmetic: Evidence for Increased Functional Specialization in the Left Inferior Parietal Cortex.Cerebral Cortex,15(11),1779-1790.https://doi.org/10.1093/cercor/bhi055

67. Schneider,M.,Beeres,K.,Coban,L.,Merz,S.,Susan Schmidt,S.,Stricker,J.,\&DeSmedt,B.(2017).Associations of non-symbolic and symbolic numerical magnitude processing with mathematical competence: A meta-analysis.Developmental Science,20(3),e12372.https://doi.org/10.1111/desc.12372

68. Shaywitz,S. E.,Shaywitz,B. A.,FulbRight,R. K.,Skudlarski,P.,Mencl,W. E.,Constable,R. T.,Pugh,K. R.,Holahan,J. M.,Marchione,K. E.,Fletcher,J. M.,Lyon,G. R.,\&Gore,J. C.(2003).Neural systems for compensation and persistence: Young adult outcome of childhood reading disability.Biological Psychiatry,54(1),25-33.https://doi.org/10.1016/S0006-3223(02)01836-X

69. Sokolowski,H. M.,Fias,W.,Mousa,A.,\&Ansari,D.(2017).Common and distinct brain regions in both parietal and frontal cortex support symbolic and nonsymbolic number processing in humans: A functional neuroimaging meta-analysis.Neurolmage,146,376-

394.https://doi.org/10.1016/j.neuroimage.2016.10.028

70. Tissier,C.,Linzarini,A.,Allaire-Duquette,G.,Mevel,K.,Poirel,N.,Dollfus,S.,Etard,O.,Orliac,F.,Peyrin,C.,Charron,S.,Raznahan,A.,Houdé,O.,Borst,G.,\&Cachia,A. (2018).Sulcal Polymorphisms of the IFC and ACC Contribute to Inhibitory Control Variability in Children and Adults.Eneuro,5(1),ENEURO.019717.2018.https://doi.org/10.1523/ENEURO.0197-17.2018

71. Tiu,R. D.,Thompson,L. A.,\&Lewis,B. A.(2003).The Role of IQ in a Component Model of Reading.Journal of Learning Disabilities,36(5),424436.https://doi.org/10.1177/00222194030360050401

72. Torre,G.-A. A.,\&Eden,G. F.(2019).Relationships between gray matter volume and reading ability in typically developing children, adolescents, and young adults.Developmental Cognitive Neuroscience,36,100636.https://doi.org/10.1016/j.dcn.2019.100636

73. van derMark,S.,Klaver,P.,Bucher,K.,Maurer,U.,Schulz,E.,Brem,S.,Martin,E.,\&Brandeis,D.(2011).The Left occipitotemporal system in reading: Disruption of focal fMRI connectivity to Left inferior frontal and inferior parietal language areas in children with dyslexia.Neurolmage,54(3),24262436.https://doi.org/10.1016/j.neuroimage.2010.10.002

74. vanEimeren,L.,Niogi,S. N.,McCandliss,B. D.,Holloway,I. D.,\&Ansari,D.(2008). White matter microstructures underlying mathematical abilities in children.Neuroreport,19(11),1117-1121.

75. Vogel,A. C.,Petersen,S. E.,\&Schlaggar,B. L.

(2014).TheVWFA:It'snotjustforwordsanymore.FrontiersinHumanNeuroscience,8.https://doi.org/10.3389/fnhum.2014.00088

76. Vogel,S. E.,Grabner,R. H.,Schneider,M.,Siegler,R. S.,\&Ansari,D.(2013).Overlapping and distinct brain regions involved in estimating the spatial position of numerical and non-numerical magnitudes: An fMRI study.Neuropsychologia,51(5),979-989.https://doi.org/10.1016/j.neuropsychologia.2013.02.001

77. Weschler,D.(2005).Weschler Intelligent Test for Children(WISC) IV.

78. Yucel,M.,Stuart,G. W.,Maruff,P.,Velakoulis,D.,Crowe,S. F.,Savage,G.,\&Pantelis,C.(2001).Hemispheric and Gender-related Differences in the Gross Morphology of the Anterior Cingulate/Paracingulate Cortex in Normal Volunteers: An MRI Morphometric Study.Cerebral Cortex,11(1),1725.https://doi.org/10.1093/cercor/11.1.17

Page $12 / 16$ 
79. Zatorre,R. J.,Fields,R. D.,\&Johansen-Berg,H.(2012).Plasticity in gray and white: Neuroimaging changes in brain structure during learning.Nature Neuroscience,15(4),528-536.https://doi.org/10.1038/nn.3045

80. Zhou,X.,Chen,Y.,Chen,C.,Jiang,T.,Zhang,H.,\&Dong,Q.(2007).Chinese kindergartners' automatic processing of numerical magnitude in Stroop-like tasks.Memory \& Cognition,35(3),464-470.https://doi.org/10.3758/BF03193286

81. Zlatkina,V.,\&Petrides,M.

(2014).MorphologicalpatternsoftheintraparietalsulcusandtheanteriorintermediateparietalsulcusofJenseninthehumanbrain.ProceedingsoftheRoyalSocietyE 20141493.https://doi.org/10.1098/rspb.2014.1493

\section{Figures}

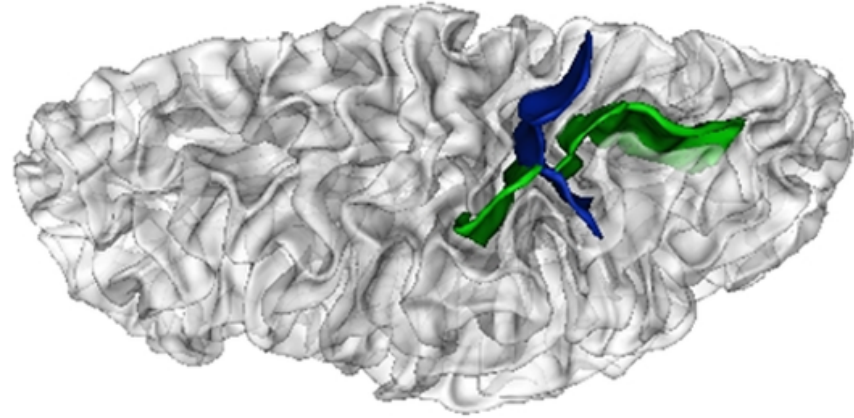

With branch sectioning IPS

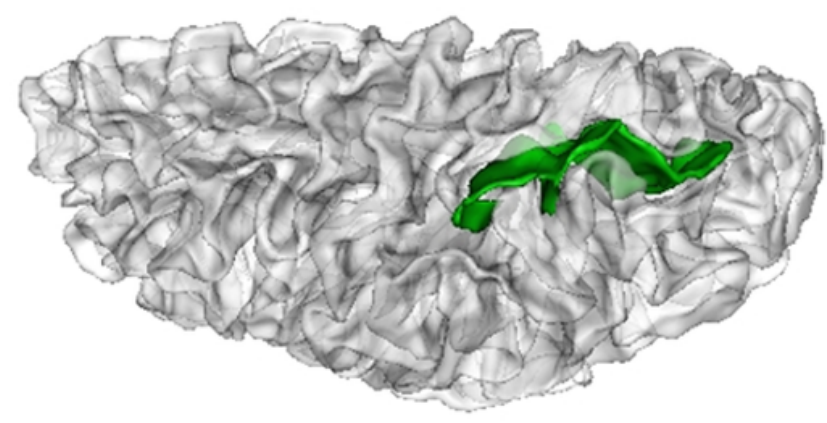

Without branch sectioning IPS

Figure 1

Sulcal patterns of the IPS. Example of a "Sectioned" (on the Left) IPS and a "Not Sectioned" IPS. The IPS sulcus is depicted in green and the branch completely sectioning the IPS is depicted in blue.

\section{Interrupted OTS}

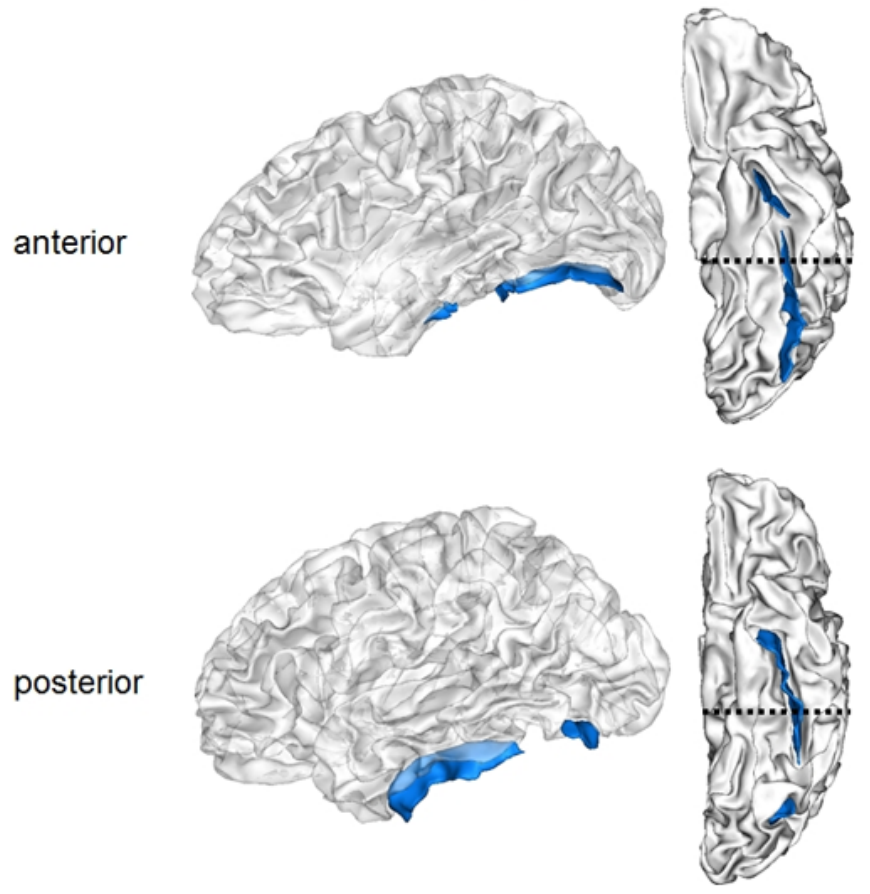

\section{Continuous OTS}
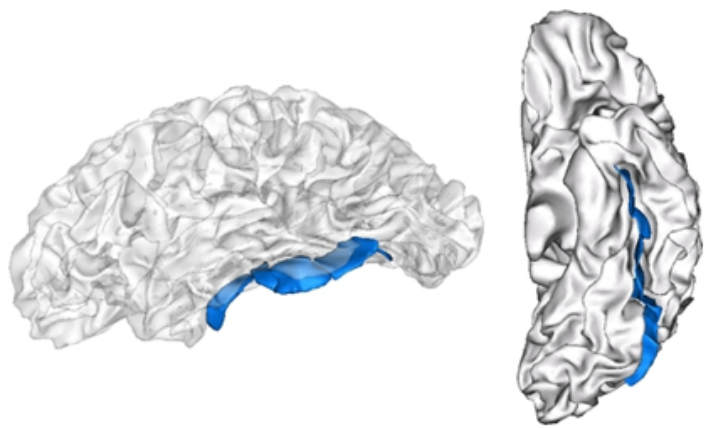

\section{Figure 2}

Example of different OTS (depicted in blue) sulcal patterns, the "interrupted" OTS on the Left and the "continuous" on the Right. Interrupted OTS were further classified as anterior (top Left) and posterior (bottom Left). The posterior extremity of the brainstem (dashed line) was used as a limit to define the anterior and posterior interruptions of the OTS. 


\section{ACC}
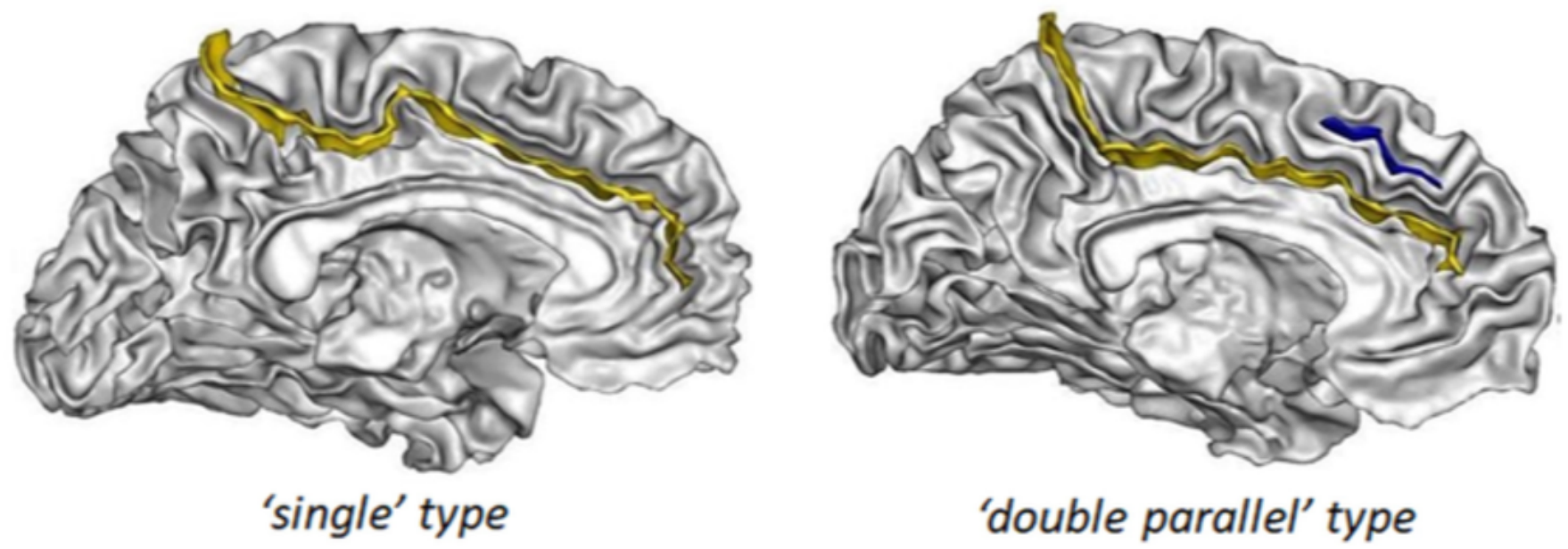

Figure 3

Example of different ACC sulcal patterns. The "single type", with only the cingulate sulcus (depicted in yellow) and the "double parallel type", with an additional PCS (depicted in blue).

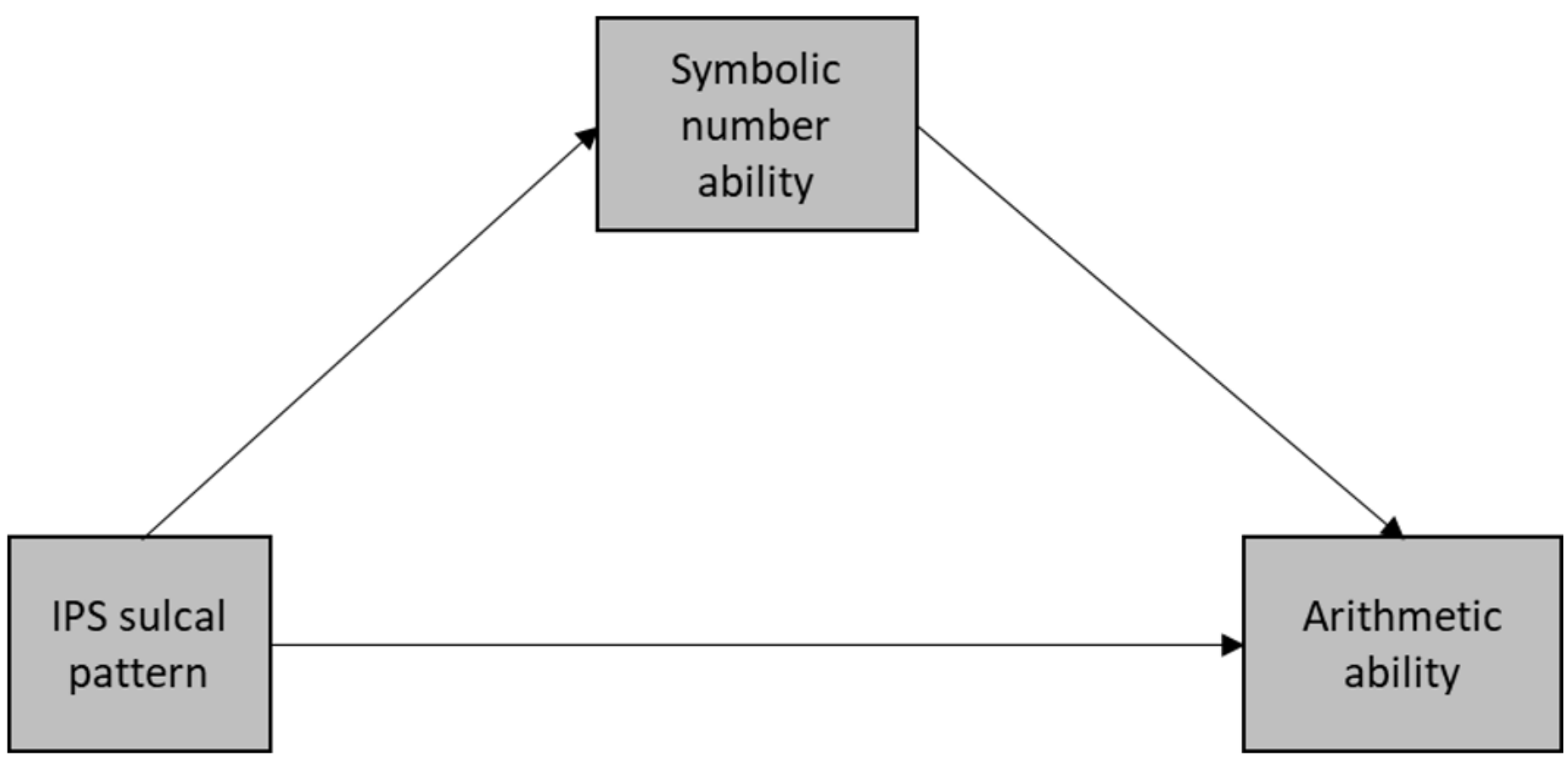

Figure 4

Mediation model for the relationship between IPS sulcal pattern and arithmetic ability as mediated by symbolic number ability. 

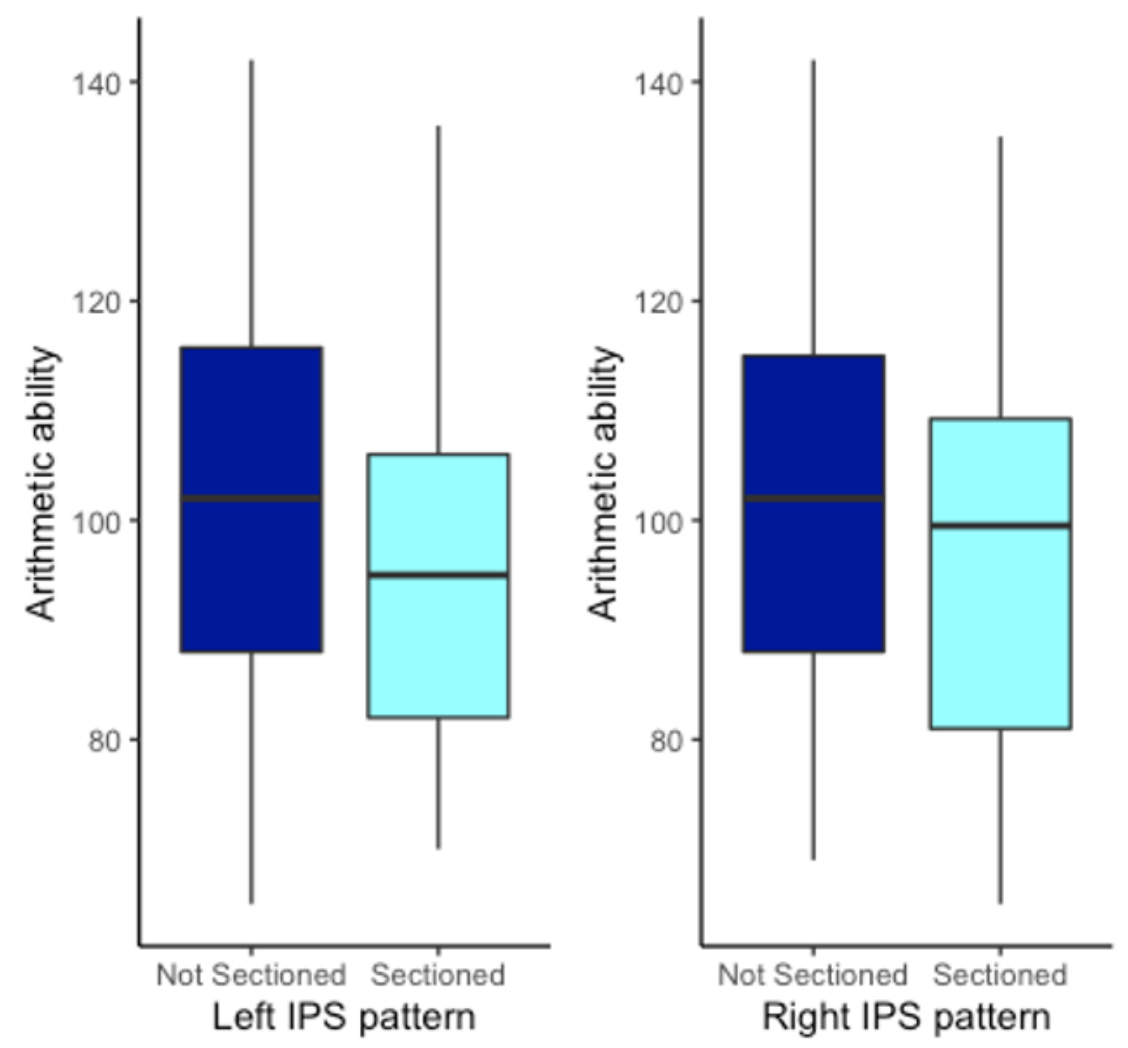

IPS pattern

Not Sectioned

宁 Sectioned

\section{Figure 5}

Effect of the Left and Right IPS pattern on arithmetic ability.
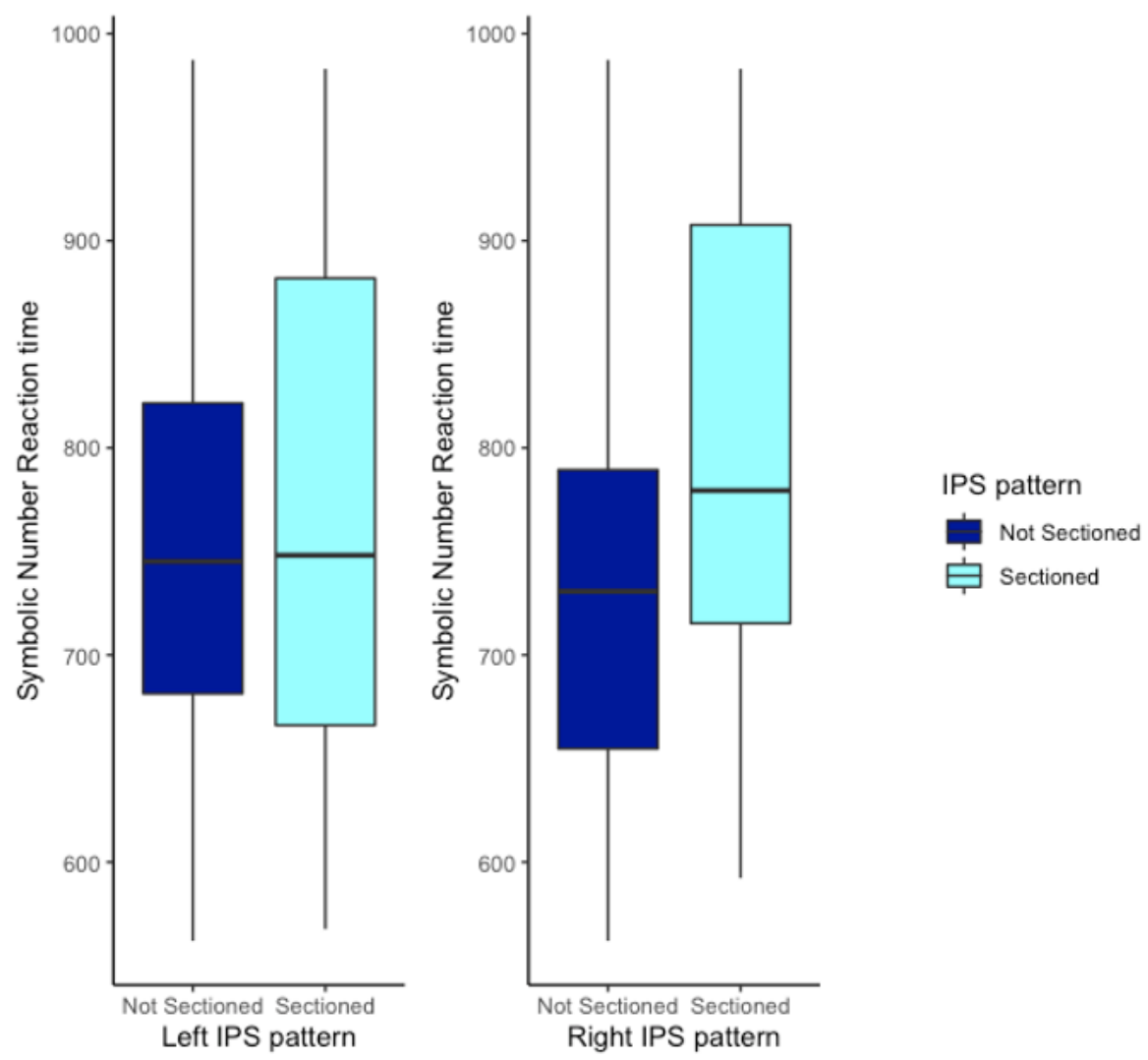

Figure 6

Effect of the Left and Right IPS pattern on symbolic number reaction time (in ms). 

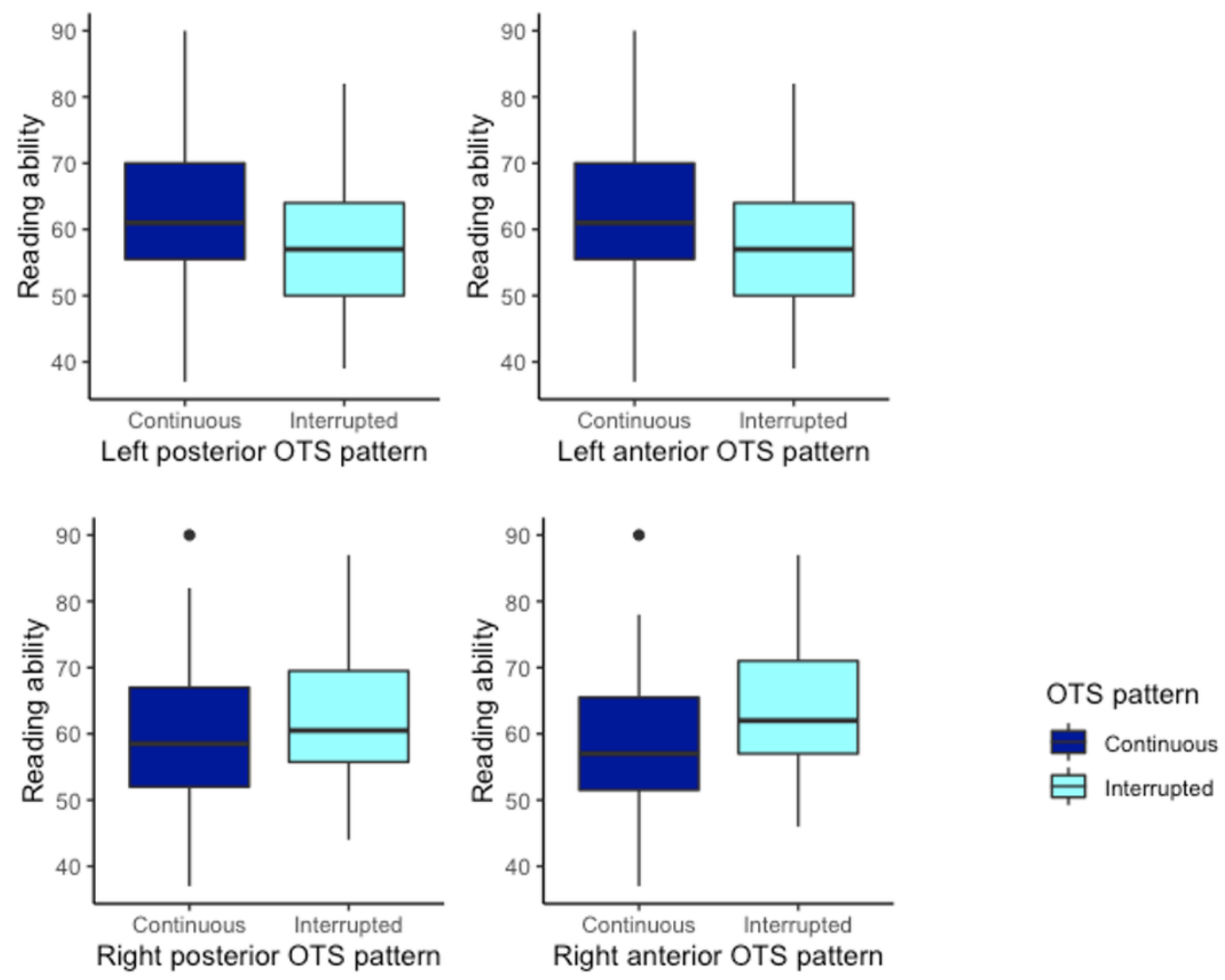

Figure 7

Effect of the four OTS patterns (Left posterior OTS, Left anterior OTS, Right posterior OTS and Right anterior OTS) on reading ability.

\section{Supplementary Files}

This is a list of supplementary files associated with this preprint. Click to download.

- SupplementaryMaterials.docx 